\title{
Ultrastructure of the optic nerve in Krabbe's leucodystrophy
}

\author{
BRIAN HARGOURT AND NORMAN ASHTON \\ From the General Infirmary, Leeds, and the Institute of Ophthalmology, University of London
}

The leucodystrophies are a heterogeneous group of inherited neurological disorders all characterized by progressive symmetrical demyelination without any marked inflammatory response, causing loss of motor, sensory, and intellectual functions with an eventual fatal outcome. Included in the group are metachromatic leucodystrophy (sulphatide lipidosis), Krabbe's globoid cell leucodystrophy, Canavan's spongy degeneration, Pelizaeus-Merzbacher disease, and Alexander's disease. All the disorders are thought to be the result of defects in normal myelin metabolism, and it is probable that there is a genetically determined enzyme defect which is specific to each clinically and histopathologically distinguishable type. The exact biochemical nature of the defect has, however, been determined only in Krabbe's disease and in sulphatide lipidosis (Moser, I972).

Krabbe's disease is a leucodystrophy of very early onset, the progressive global deterioration of cerebral function commencing within a few weeks of birth (Krabbe, I9I6). Affected infants fail to thrive and become increasingly irritable with characteristic bouts of inconsolable crying. Tonic seizures and spastic quadriplegia develop and most affected children become deaf and also blind as the result of optic atrophy before they die, in a decerebrate state, in the second year of life, usually from the intervention of a severe respiratoryinfection. The demyelinating process is characteristically associated with the accumulation of epithelioid cells and of large multinucleated globoid cells in the degenerate white matter (Collier and Greenfield, 1924). The disease follows an autosomal recessive pattern of inheritance, and a deficiency of the enzyme galactocerebroside beta-galactosidase has been demonstrated recently, not only in the brain but also in the viscera, leucocytes, and serum of patients with Krabbe's disease (Suzuki and Suzuki, r970, 197 I). Total glycolipids are reduced in the brain, typically with an increase in the ratio of cerebrosides to sulphatides, and there is also a low level of cerebroside sulphotransferase activity (Bachhawat, Austin, and Armstrong, 1967). The exact mechanism by which the inherited enzyme defect gives rise to the characteristic biochemical, neurological, and histopathological manifestations of the disease is not yet fully understood. The reason for the relative decrease in cerebroside concentration in the brain, despite a defect in its catabolic pathway, is thought to be reduced synthesis of cerebroside by the oligodendrocytes which decrease in number early in the disease on account of the massive accumulation of globoid cells within the white matter (Suzuki and Suzuki, I970).

Light-microscopic studies (Norman, Oppenheimer, and Tingey, I96r ; D’Agostino, Sayre, and Hayles, 1963) have demonstrated that globoid cells tend to have a perivascular distribution within the cerebral white matter, and that they appear and increase in number during the period of myelin breakdown. Accumulations of periodic acid-Schiff-positive 
material are present initially extracellularly, but later within the numerous globoid cells. This material is probably composed of the breakdown products of demyelination which are being phagocytosed by microglial cells that become converted to globoid cells. It has not been possible at a light-microscopic level to determine the exact nature of the PASpositive intracellular material, but during the last few years there have been several reports of the ultrastructure of cerebral biopsies and of post-mortem cerebral specimens in this disease, and characteristic cytoplasmic inclusions in the epithelioid and globoid cells have been described (Nelson, Aurebeck, Osterberg, Berry, Jabbour, and Bornhofen, ڤึ I963; Schochet, Hardman, Lampert, and Earle, I969; Yunis and Lee, I969, I970, I972; Suzuki and Grover, 1970; Andrews and Cancilla, 1970; Liu, 1970; Shaw and Carlson, 1970). The inclusions most commonly occur in the form of moderately electron-dense straight or slightly curved tubular structures, and there is strong circumstantial evidence suggesting that they represent an intracellular deposition of galactocerebroside; somewhat similar tubules have been observed in the glucocerebroside of Gaucher's disease and in bovine galactoside-further confirmation of the biochemical nature of the globoid cell inclusions (Yunis and Lee, I970).

Blindness is a significant feature of the later stages of Krabbe's disease because of degenera- 을 tive changes in the afferent visual pathways, both at the optic nerve fibre and optic radiation level. The first description of the post-mortem pathological findings in the optic nerve and the eye (Emery, Green, and Huff, 1972) included a brief description of the ultrastructure of globoid cells in the patient's optic nerve. A gross reduction in the ganglion cell and nerve fibre layers of the retina was reported; the cytoplasm of globoig cells seen in optic nerve sections contained long curved inclusions similar to those whic had previously been described by other authors in the cerebral white matter. Such chang in the optic nerve were also described by Yunis and Lee (1972).

The purpose of the present communication is to report another pathological examination of the eyes, together with an ultrastructural study of the optic nerve of a child affected by Krabbe's disease.

\section{Case report}

The patient was a Caucasian baby girl, the third child of unrelated parents; she was born at term by elective Caesarean section and the neonatal period was uneventful.

The first child had been born 5 years previously and had died at the age of 10 months, having been affected by a progressive neurological degenerative disease. A diagnosis of Krabbe's leucodystrophy had been made post mortem at another hospital when globoid cells were noted in lightmicroscopic preparations from the degenerate white matter.

A second child born 2 years later was making normal progress.

By the time the patient had reached the age of 5 months the parents were concerned by her $\frac{D}{3}$ general lack of development. Bouts of inconsolable crying and a failure to thrive were noted particularly, features which had become apparent in the first child at a similar age.

\section{Examination}

At ro months the child was first admitted, in the care of Dr. John Wilson, to the Hospital for Sick Children, Great Ormond Street, London, with hypertonic quadriplegia and an absence of $\varrho$ response to all forms of visual stimuli apart from a blink response to threat and to bright light. Constant wandering eye movements were present and the pupillary light reflexes were very sluggish; the optic discs were pale. The electroencephalogram record showed a generalized abnormality of cerebral function with multifocal discharges which became more marked as the disease progressed. 
Electromyographic studies demonstrated a gross slowing of motor conduction times in peripheral nerves in the limbs. The cerebrospinal fluid protein concentration was $120 \mathrm{mg}$./10o ml. A sural nerve biopsy demonstrated a segmental demyelinating process.

\section{Termination}

The general condition deteriorated progressively and the child died of broncho-pneumonia at the age of 18 months.

Post-mortem examination of the brain revealed the presence of numerous globoid cells in the white matter, confirming the clinical diagnosis of Krabbe's disease. The eyes were removed within 2 hours of death and a portion of the left optic nerve was fixed in 4 per cent. buffered glutaraldehyde solution, and then post-fixed in I per cent. osmium tetroxide and embedded in Araldite. Both globes were fixed in to per cent. formol saline.

\section{Pathology}

MAGROSGOPICAL EXAMINATION

Both globes were opened horizontally and no gross abnormality was found. Celloidin sections of both eyes and transverse and longitudinal paraffin and frozen sections of the left optic nerve were prepared.

\section{MICROSGOPICAL EXAMINATION}

Both eyes showed attenuation of the nerve fibre layer and a paucity of ganglion cells in the retina with atrophic changes in the optic discs and moderate gliosis of the nerves themselves. Scattered throughout the nerves there were a few moderately large cells, mononuclear or multinucleate, with PAS-positive staining cytoplasm, resembling globoid cells (Fig. I). Oil red $\mathrm{O}$ staining of the frozen section was negative. No specific diagnosis could be made by light microscopy.
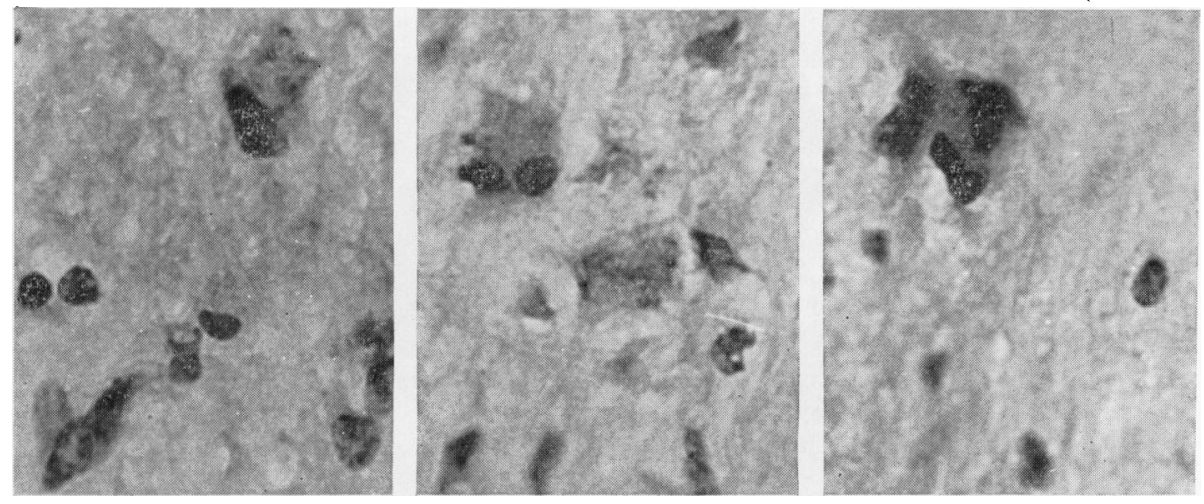

FIG. I Mono- and multinucleate "globoid cells" in optic nerve. Periodic acid-Schiff and haematoxylin. $\quad \times 720$

\section{ELECTRON MIGROSGOPY OF LEFT OPTIC NERVE}

In contrast to the relatively mild pathological changes found by light microscopy, electron microscopy revealed considerable distortion of the normal architecture of the nerve with pronounced axonal swelling and myelin degencration (Fig. 2). To what extent this may have been due to post-mortem autolysis could not, however, be determined. Scattered throughout the nerve, especially in relation to areas of myelin degeneration, there were 


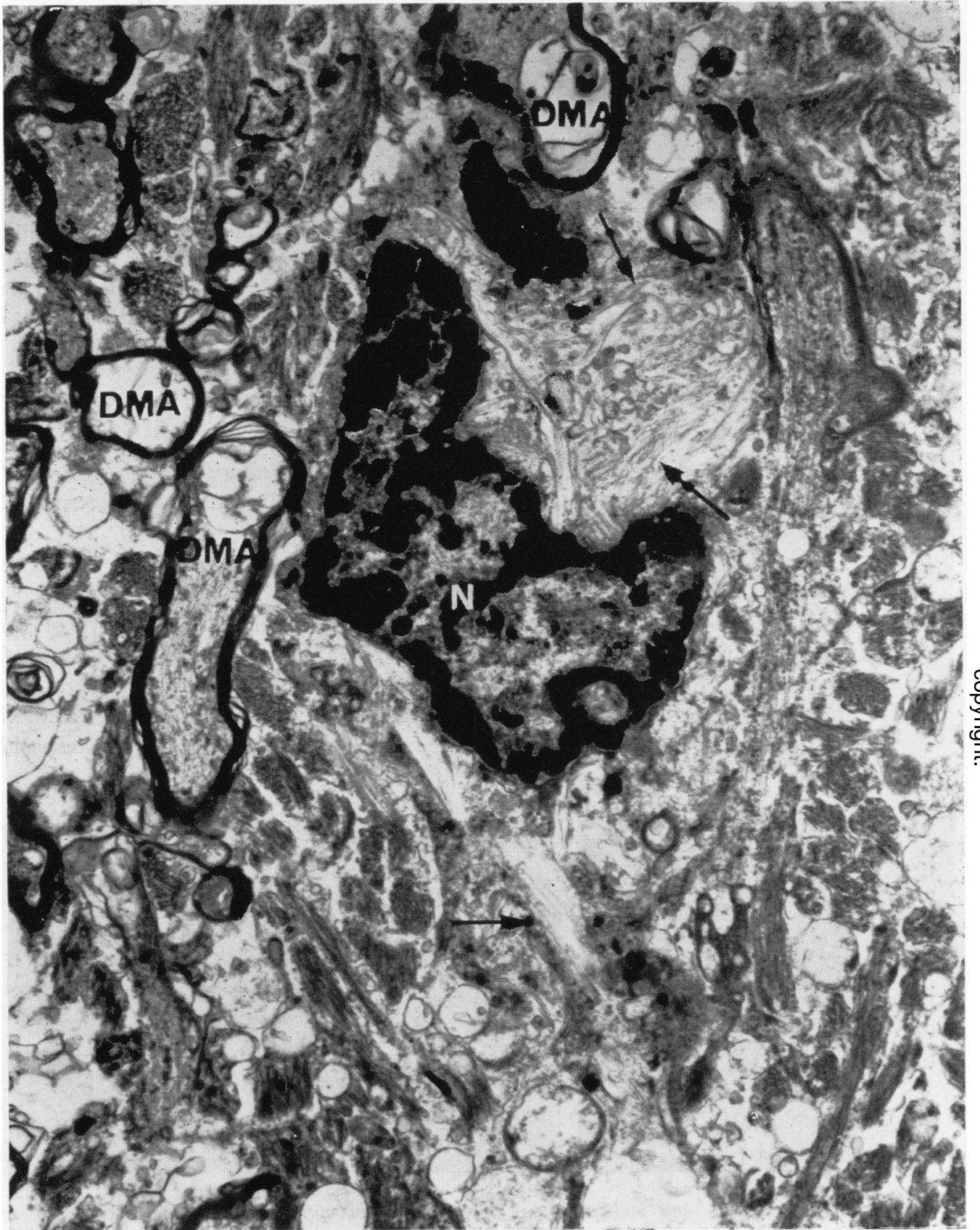

FIG. 2 Electron micrograph of optic nerve, showing degenerate myelinated axons (DMA) lying adjacent to a large microglial cell with indented nucleus $(\mathcal{N})$ and cytoplasmic tubular inclusions (arrows). $\quad \times 14,500$

a number of large cells with irregular or indented nuclei, which were considercd to be microglial cells (Fig. 2). These cells contained, within their abundant cytoplasm, abnormal deposits consisting of whorls of curved, angulated, or straight tubules intermingling with fibrils, numerous vesicles of varying sizes, aggregates of glycogen granules, swollen degener- 


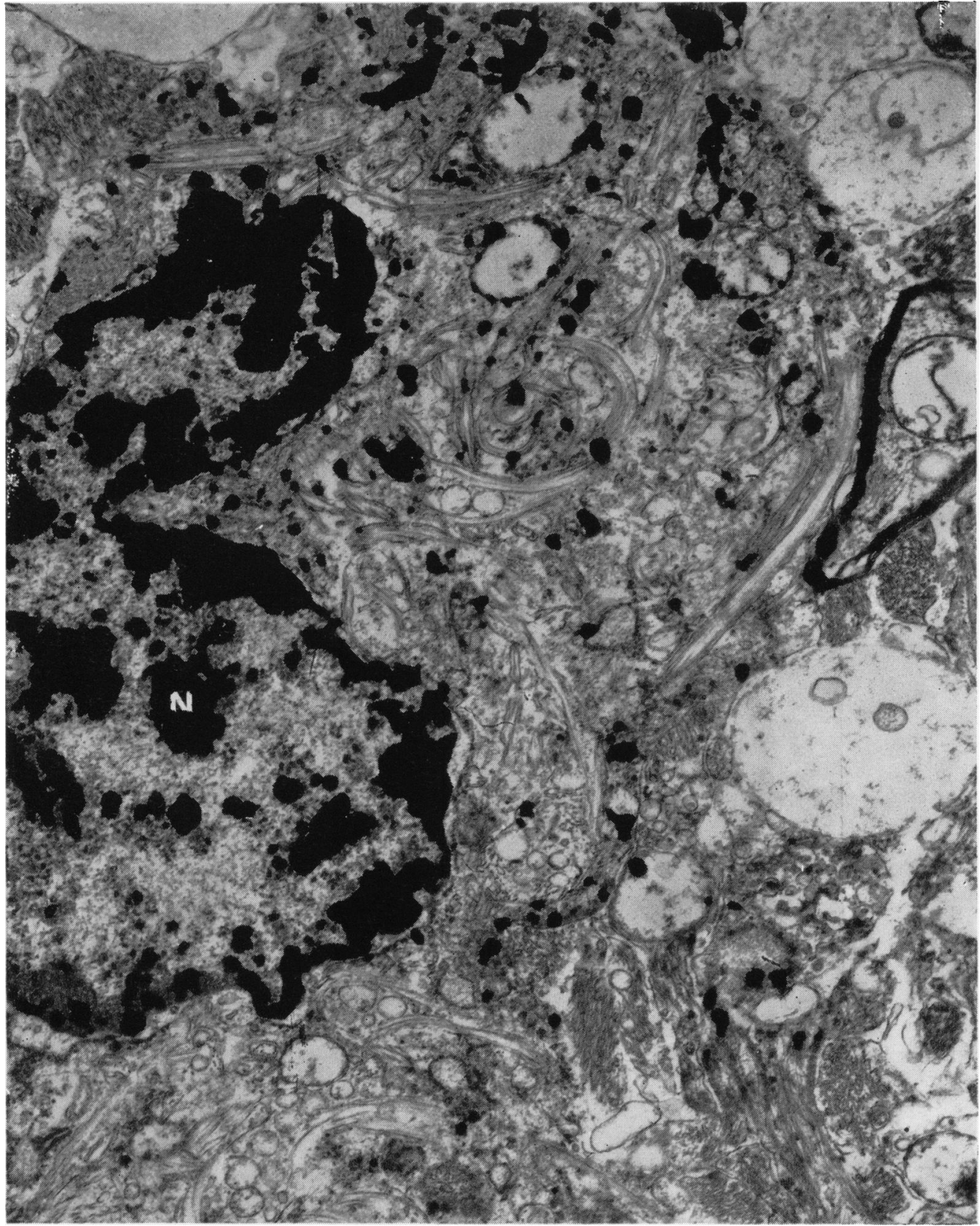

FIG. 3 Electron micrograph, showing higher-power view of cytoplasmic tubular inclusions underlying the nucleus $(\mathcal{N})$. They are seen to be curved, angulated, and straight, and they intertwine to give a whorled appearance. $\times 22,100$

ate mitochondria, and other organelles (Fig. 3). Higher power showed the tubules to have a fibrillar substructure, to vary considerably in width $\left(75^{-1} 80 \mathrm{~nm}\right)$, and to consist of a central electron-lucent core (25-90 $\mathrm{nm}$ ) surrounded by parallel electron-dense lamina- 


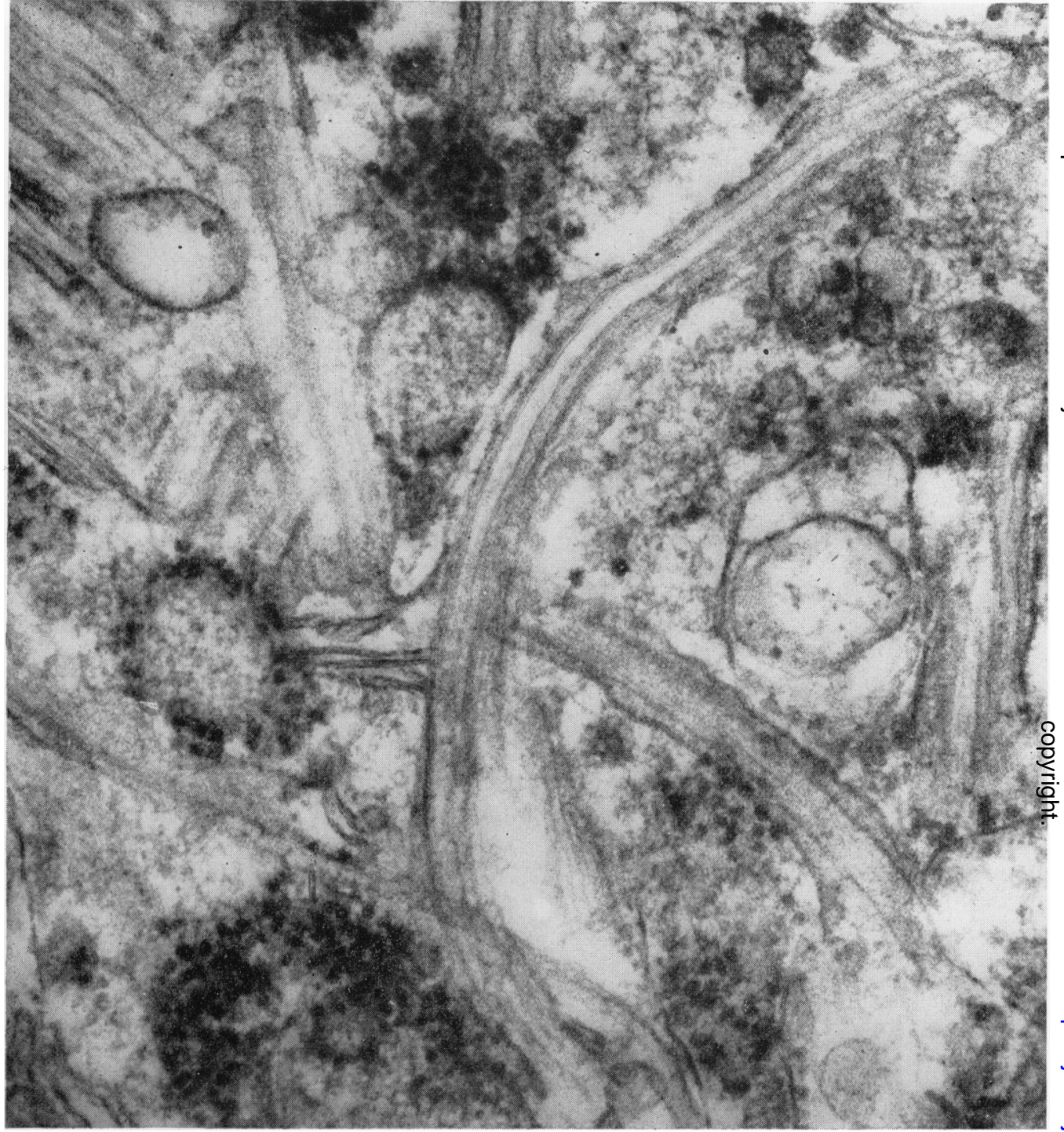

FIG. 4 Electron micrograph, showing tubules to consist of a central core surrounded by electron dense parallel lamellae. Curved and straight forms are seen and aggregates of glycogen granules are present in the surrounding cytoplasm. $\times 84,000$

tions set at irregular intervals (Fig. 4). These appearances correspond exactly to those described by others in macrophage inclusions in globoid leucodystrophy, and further 疋 substantiate the clinical and histopathological diagnosis. These ultrastructural appear- No ances have been described only twice previously in the optic nerve (Emery, Green, and $\mathrm{N}$ Huff, 1972; Yunis and Lee, 1972).

\section{Summary}

The histopathological appearances in the eyes of a case of Krabbe's leucodystrophy are described, and the ultrastructural changes in the optic nerve are illustrated. 
We are most grateful to Dr. J. Wilson, Consultant Neurologist at the Hospital for Sick Children, Great Ormond Street, London, for kindly allowing us to report the clinical details of this case, and to Dr. Brian Lake, Institute of Child Health, London, for his assistance. Our thanks are due to Mr. G. Knight and Mr. D. Wood for technical assistance and to Miss E. FitzGerald for secretarial help.

\section{References}

andrews, J. M., and cancilla, P. A. (1970) Arch. Path., 89, 53

BAChHAWAt, B. K., Austin, J., and ARmStrong, D. (1967) Biochem. 7., ro4, I50

COLliER, J., and GREENFIELD, J. G. (1924) Brain, 47, 489

D'agostino, A. N., Sayre, G. P., and hayles, A. B. (1963) Arch. Neurol. (Chicago), 8, 82

emery, J. M., Green, w. R., and huff, D. s. (1972) Amer. J. Ophthal., 74, 400

KRABBE, K. (I9I6) Brain, 39, 74

LIU, н. м. (I970) J. Neuropath. exp. Neurol., 29, 44I

moser, H. W. (1972) In "The Metabolic Basis of Inherited Disease", 3rd ed., ed. J. Stanbury,

J. B. Wyngaarden, and D. S. Fredrickson, p. 688. McGraw-Hill, New York

Nelson, E., AUrebeck, G., OSterberG, K., Berry, J., JAbbour, J. T., and bornhofen, J. (I963)

J. Neuropath. exp. Neurol., 22, $4 \mathrm{I} 4$

Norman, R. M., oppenheimer, D. R., and tingey, A. H. (I96I) J. Neurol. Neurosurg. Psychiat., 24, 223 schochet, s. s., JR., hardman, J. M., lampert, p. w., and e.arle, K. м. (1969) Arch. Path., 88, 305 SHAW, c. M., and CARLSON, c. B. (1970) J. Neuropath. exp. Neurol., 29, 306

SUzUKI, K., and Grover, W. D. (1970) Arch. Neurol. (Chicago), 22, 385

- and suzuki, y. (1970) Proc. nat. Acad. Sci., (Wash.), 66, 302

SUZUKI, Y., and suZUKI, K. (I97I) Science, r7r, 73

YUNIS, E. J., and LEE, R. E. (1969) Lab. Invest., 21, 415

- (1970) Science, 169, 64

( 1972) Hum. Path., 3, 37 I 